\title{
Redex: A Language for Lightweight Semantics Engineering (Keynote)
}

\author{
Robby Findler \\ Northwestern University \& PLT, USA \\ robby@eecs.northwestern.edu
}

\begin{abstract}
Redex is a programming language designed to support semantics engineers as they experiment with programming language models. To explore a model, an engineer writes down grammars, type systems, and operational semantics in a notation inspired by the programming languages literature. Redex breathes life into the model, building typing derivations, running example expressions, and using random generation to falsify claims about the model.
\end{abstract}

The talk first gives an overview of Redex, motivating its design choices and giving a sense of how programming in Redex feels. Then the talk dives into some of the techniques that Redex uses to generate random expressions.

Categories and Subject Descriptors D.2.5 [Testing and Debugging]: Testing tools; D.1.1 [Applicative (Functional) Programming]

Keywords semantics engineering, Redex, random testing

Permission to make digital or hard copies of all or part of this work for personal or classroom use is granted without fee provided that copies are not made or distributed for profit or commercial advantage and that copies bear this notice and the full citation on the first page. Copyrights for components of this work owned by others than ACM must be honored. Abstracting with credit is permitted. To copy otherwise, or republish, to post on servers or to redistribute to lists, requires prior specific permission and/or a fee. Request permissions from Permissions@ acm.org.

Copyright is held by the owner/author(s). Publication rights licensed to ACM.

SLE'16, October 31 - November 1, 2016, Amsterdam, Netherlands

ACM. 978-1-4503-4447-0/16/10...\$15.00

http://dx.doi.org/10.1145/2997364.2998391 